\begin{tabular}{|l|c|c|}
\hline & \multicolumn{3}{|c|}{ Eurasian Academy of Sciences } \\
\hline & Eurasian Econometrics, Statistics \& Emprical Economics Journal \\
Published Online April 2015 (http://econstat.eurasianacademy.org) & S: 65 - 79 \\
\hline
\end{tabular}

\title{
The Effect of the Financial Ratios on Foreign Investors' Choices of Stock: An Empirical Application on ISE
}

Yrd. Doç. Dr. İbrahim BOZKURT *

Çankırı Karatekin Üniversitesi, İ.İ.B.F., Bankacılık ve Finans Bölümü*

E-mail:ibozkurt@karatekin.edu.tr*

Copyright (C) 2015 Yrd. Doç. Dr. İbrahim BOZKURT. This is an open access article distributed under the Eurasian Academy of Sciences License, which permits unrestricted use, distribution, and reproduction in any medium, provided the original work is properly cited.

\begin{abstract}
In the literature, many studies which aim to determine factors affecting investment decisions of foreign investors were done, because foreign investments have importance with regard to national economies, capital markets and firms. In the related studies, lots of factors were investigated for explaining the causes of the foreign capital mobility, but the effect of the financial ratios on the foreign capital mobility was not investigated comprehensively. The main purpose of this study is to investigate the effect of the financial ratios of firms traded in ISE on foreign investors' choices of stock. For this purpose, in this study, data of three-month financial statements of 193 firms traded on ISE between 2004/12-2014/09 and net quantities of stocks bought and sold by foreign investors were used as data. At the end of this study which used panel data regression methodology, it was revealed that foreign investors prefer the stocks of firms which increase net profit margin, current ratio and debt to equity ratio of theirs and decrease inventory turnover and short term financial debt to short term debt ratio of theirs.
\end{abstract}

Keywords: Financial Ratios, Foreign Investors, Choice of Stock, ISE, Panel Data Analysis.

\section{Finansal Rasyoların Yabancı Yatırımcıların Hisse Seçimine Etkisi: Borsa İstanbul'da Ampirik Bir Uygulama}

ÖZET : Yabancı yatırımların ülke ekonomileri, sermaye piyasaları ve firmalar açısından önem arz etmesi nedeniyle yazında, yabancı yatırımcıların yatırım kararlarına etki eden faktörlerin belirlenmesini amaç edinen çokça çalışma yapılmıştır. İlgili çalışmalarda, yabancı sermaye hareketlerinin nedenlerini açıklamak için birçok faktör incelenmiş; ancak firmalara ait finansal rasyoların, yabancı sermaye hareketleri üzerindeki etkisi ayrıntılı bir şekilde irdelenmemiştir. Bu çalışmanın temel amacı; Borsa İstanbul'da işlem gören firmalara ait finansal tablo rasyolarının, yabancı portföy yatırımcılarının hisse senedi tercihleri üzerindeki etkisini incelemektir. Belirlenen amaç doğrultusunda çalışmada, hisseleri Borsa İstanbul'da işlem gören 193 firmanın 2004/12-2014/09 dönemi aralığındaki 3'er aylık finansal tablo verileri ile her bir firma için yabancı yatırımcıların aylık net hisse alım-satım miktarları veri 
olarak kullanılmıştır. Verilerin panel veri regresyon analiz yöntemi ile analiz edildiği çalışma sonucunda, yabancı yatırımcıların; net kar marjını, cari oranını ve borç/özsermaye oranını artıran buna karşın stok devir hızını ve FKV oranını düşüren firma hisselerini tercih ettikleri ortaya konulmuştur.

Anahtar Kelimeler: Finansal Rasyolar, Yabancı Yatırımcılar, Hisse Tercihi, Borsa İstanbul, Panel Veri Analizi.

\section{GİRIŞ}

Yabancı yatırımcılara ait sermayenin sınır ötesindeki hareketleri denildiğinde, akla, "doğrudan yatırımlar" ve "portföy yatırımları" olarak adlandırılan iki önemli yabancı yatırım türü gelmektedir. Ülkeler arasındaki sermaye hareketinin bir piyasa işlemi olmadan gerçekleşmesini ifade eden doğrudan yabancı sermaye yatırımları; ya bir başka ülkede işletme kurularak ya da yabancı bir ülkedeki işletmeye sermaye yatırılarak gerçeklleştirilir (Bayraktar, 2003: 5). Doğrudan yatırımların aksine portföy yatırımları ise direkt olarak işletme kurma ya da işletmeye katılma yerine, fonların, çeşitli menkul kıymetlere yatırılarak kullanılmasını ifade etmektedir (Yalçıner, 2008: 88). Yabancılar tarafından yapılan portföy yatırımları, ortaklık ya da alacak hakkı veren finansal varlıklara yönelik yatırımlardır. Bu çalışma, hisse senetlerine yönelik olan yabancı portföy yatırımlarını temel almaktadır ${ }^{1}$.

Hisse senedi piyasalarında yerli yatırımcıların yanında yabancı yatırımcılara da yatırım imkânı verilmesi, farklı türdeki yabancı yatırımcıların yüksek kazanç arayışı içerisinde sınır ötesi hareket etmesini sağlamıştır (Ameer, 2010: 126). Küreselleşme ile birlikte özellikle gelişmekte olan ülke borsalarındaki yabancı yatırımcıların payı önemli derecede artmıştır. Borsalardaki yabancı payı artışı; yatırımcıların, (i)aynı ekonomik ortamda portföy oluşturdukça tamamen ortadan kaldıramadıkları sistematik riski, uluslararası çeşitlendirme ile yok etmeyi (Yalçıner, 2008: 95) ve (ii)fonlarını, verimliliğin fazla olduğu piyasalarda kullanmayı (Fischer ve diğerleri, 1998: 32) amaç edinmiş olmaları ile açıklanabilir. Bu ve buna benzer amaçların gerçekleştirilmesi düşüncesi ve bir takım unsurların varlığ ${ }^{2}$ nedeniyle artış gösteren yabancı sermaye yatırımları, ülkelerin ekonomik anlamdaki büyümesine destek sağlayacak sermaye birikiminin sağlanmasına, sağladığı döviz girişi ile uzun vadede ihracatın artmasına ve ödemeler dengesi gibi göstergelerin iyileşmesine olumlu yönde tesir etmekte; ayrıca sermaye piyasalarının gelişmesine ve canlanmasına da katkı sağlamaktadır (Sağlamer, 2003: 3-5). Yabancı sermaye yatırımları, ülke ekonomilerine ve sermaye piyasalarına olduğu kadar, yatırım yapılan hisse senetleri aracılığılla ortak olunan firmaların yönetim etkinliğine de olumlu yönde tesir etmektedir. Şöyle ki özellikle kurumsal yatırımcılar tarafından yapılan yabancı sermaye yatırımları, (i)gereksiz stok artışlarından kaçınarak stok yönetiminde, yatırım fırsatlarını kaçırmamak için de nakit yönetiminde etkinliği artırmakta ve (ii)firmalarda kurumsal yönetim anlayışının benimsenmesine katkı sağlamaktadır (Ameer, 2010). Sözü edilen faydalarına karşın, özellikle gelişmekte olan ülkeler gibi sağlam ekonomik temellerin olmadığı piyasalardaki yabancı sermaye yatırımları, birtakım olumsuzluklara da neden olabilmektedirler. Yabanc1 sermayenin sahip olduğu hareketlilik, yabanc1 sermaye yatırımlarının en önemli olumsuzluğudur. Getiri ve faiz oranlarındaki değişkenlik, vergi mevzuatının ülkeler arasında farklılaşması, döviz kurlarındaki oynaklık ile ülkenin kredi

\footnotetext{
${ }^{1} \mathrm{Bu}$ nedenle çalışmanın bundan sonraki bölümlerinde yabancı portföy (hisse) yatırımları yerine, yabancı sermaye yatırımı; yabancı portföy (hisse) yatırımcısı yerine de yabancı yatırımcı kavramı kullanılmıştır.

${ }^{2}$ Yabancı sermaye yatırımlarını artıran unsurlar arasında; ülkelerdeki siyasi yapının iyileşmesi, yapısal reformlar ve yüksek getiri imkânları gibi yabancı yatırımcıyı cezbeden gelişmeler bulunmaktadır.
} 
değerliliğindeki, ekonomik ve siyasi yapısındaki dalgalanmalar gibi faktörler, yabancı sermayenin farklı piyasalar arasında hizlı ve ani bir şekilde hareket etmesine neden olmaktadır. Yabancı yatırımcıların piyasalardan çıkarken yaptı̆̆ı hisse satışları, ilgili ülke borsasında ani düşüşlere ve nihayet krizlerin çıkmasına neden olabilmektedir. Şekil 1, yabancı sermaye hareketlerinin hisse senedi piyasası üzerindeki etkisinin büyüklügünü, Türkiye özelinde göstermektedir.

Şekil 1: Yabancı Sermayenin ve BİST-100 Endeksinin Y1llık Seyri (1997-2014).

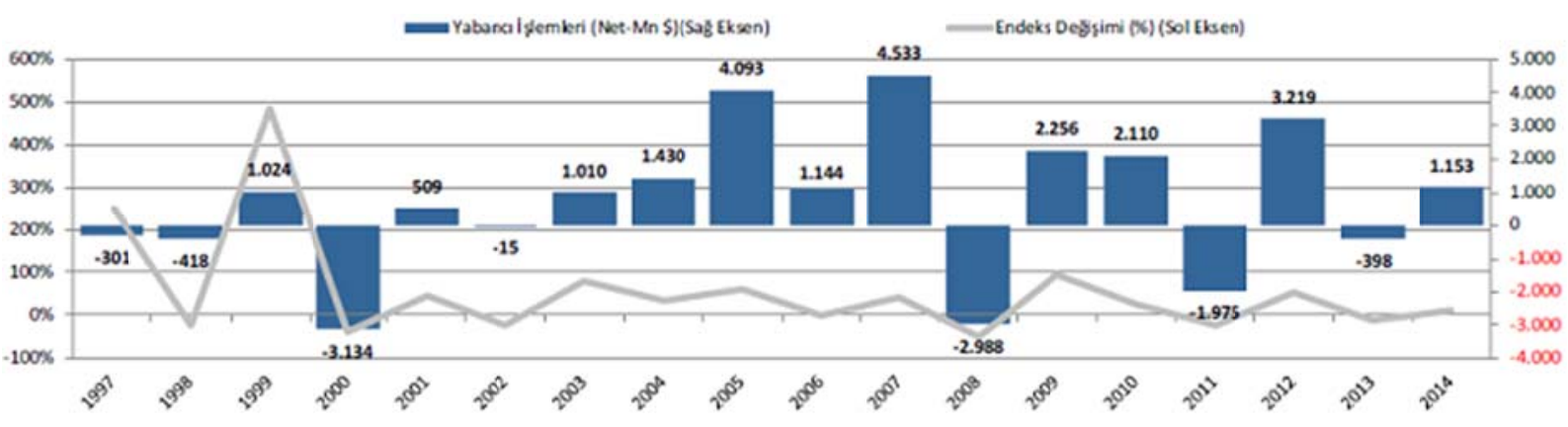

Kaynak: Sayın (2014: 2).

Yabancıların piyasadan çıkarken yaptığı satışların krizlere kadar varan etkisi, yabancı yatırımcının özellikle gelişmekte olan piyasalarda sahip olduğu sermayenin büyüklüğünden kaynaklanmaktadır. Tablo 1, yabancı yatırımcıların hisse senedi piyasasında sahip olduğu portföy büyüklüğünü, Türkiye özelinde göstermektedir.

Tablo 1: Yabancı Yatırımcıların Türkiye'deki Portföy Büyüklügüü.

\begin{tabular}{ccc}
\hline Dönem & Hisse Değeri (Milyon \$) & Hisse Değeri Oranı (\%) \\
\hline 31 Aralık 2013 & 78.545 & 65,77 \\
31 Ocak 2014 & 48.928 & 61,29 \\
28 Şubat 2014 & 50.971 & 61,23 \\
31 Mart 2014 & 53.670 & 63,02 \\
30 Nisan 2014 & 63.563 & 63,45 \\
30 Mayıs 2014 & 69.464 & 64,14 \\
30 Haziran 2014 & 67.992 & 63,67 \\
31 Temmuz 2014 & 71.275 & 64,48 \\
29 Ağustos 2014 & 68.513 & 64,11 \\
10 Eylü1 2014 & 66.373 & 64,28 \\
\hline
\end{tabular}

Yabancıların piyasadan çıkarken yaptığ 1 satışların hisse fiyatlarında önemli bir düşüşü beraberinde getirmesinin bir diğer nedeni de "bedava binici sorunu -free rider problem" olarak tanımlanan etkinin varlığı nedeniyle, yatırımcıların, yabancı sermaye hareketlerini takip ederek yatırımlarına yön vermesidir. Bu ifadeleri doğrulayıcı nitelikte olan Kamesaka vd.'nin (2003) Japonya piyasasında yaptıkları çalışmada, yabancı yatırımcıların bilgi temelli, yerli yatırımcıların ise davranışsal temelli hareket ettiği ortaya konulmuştur.

Yabancı yatırımların ülke ekonomisi, sermaye piyasaları ve firmalar üzerinde, yukarıda dile getirilen olumlu ve olumsuz etkileri, yazında, yabancı yatırımciları temel alan ve bu yatırımcıların yatırım kararlarına etki eden faktörlerin belirlenmesini amaç edinen çokça çalışmanın yapılmasını sağlamıştır (Tablo 2). Yazında yer alan çalışmalarda (Tablo 2), yabancı sermaye hareketlerinin nedenlerini açıklamak için birçok faktör incelenmiş; ancak firmalara ait finansal rasyoların, yabancı sermaye hareketleri üzerindeki etkisi ayrıntılı bir şekilde irdelenmemiştir. 
Bu noktada, bu çalışmanın temel amacı; Borsa İstanbul (BİST)'da işlem gören firmalara ait finansal tablo verilerinin (rasyolarının), yabancı portföy yatırımcılarının hisse senedi tercihleri üzerindeki etkisini incelemektir.

Çalışmanın bundan sonraki bölümlerinde sırasıyla konu ile ilişkili olarak literatürde yer bulan çalışmalara, çalışmanın veri ve metodolojisine ilişkin bilgilere, çalışmanın bulgularına ve sonuçlarına yer verilecektir.

\section{LITERATÜR TARAMASI}

Yabancı yatırımcıların yatırım (hisse) tercihlerini etkileyen, diğer bir ifadeyle de yabancı sermaye hareketlerine neden olan faktörlerin bilinmesi; (i)uluslararası sermaye hareketlerinin neden olacağı olumsuz ekonomik etkilerin bertaraf edilmesi için alınacak önlemelerin, (ii)hisse senedi piyasalarını kullanarak fon temin etmek isteyen firmaların önem göstereceği hususların, (iii)portföy oluşturma sürecinde yerli yatırımcılarca oluşturulacak stratejilerin ve (iv) yabancı sermaye yatırımlarından sağlanacak olan faydaların nasıl maksimize edileceğinin, tespiti açısından önemlidir. Bu öneminden dolayı, literatürde yer bulan ve yabancı yatırımcıların hisse tercihlerine etki eden faktörlerin belirlenmesini amaç edinen çalışmalar, kullandıkları veri seti, yöntemleri ve elde ettikleri sonuçlarıyla birlikte Tablo 2'de özetlenmiştir.

Tablo 2, yabancı yatırımcılarca tercih edilen firmaların özelliklerini irdeleyen çalışma sonuçlarına odaklanmış olup; yabancı sermayenin yöneldiği ülkelere ait özellikleri irdeleyen çalışmaları, konu gereği, kapsam dışında tutmuştur. Yabancı sermaye hareketlerine neden olan ülkesel faktörleri irdeleyen çalışmalar genel olarak; piyasadaki yüksek getiri imkânlarının, yapısal reformların, politik gelişmelerin, özelleştirme faaliyetlerinin, döviz kurlarının ve faiz oranları gibi faktörlerin yabancı yatırımcıların piyasa tercihine etki ettiğini tespit etmiştir (Yalçıner, 2008: 96).

Yabancı yatırımcıların hisse tercihlerine etki eden faktörlerin tespitine yönelen çalışmalarda (Tablo 2), genel olarak yabancı payı, bağımlı değişken olarak analizlere dâhil edilmişken kullanılan bağımsız değişkenler çalışma bazında farklılık göstermiştir. Kaldıraç oranı, cari oran, aktif ve özsermaye karlılığı, hisse betası, PD/DD oranı, ihracat gelirleri, temettü kazanc1, likidite düzeyi, hisse getirileri, firmaların kurumsallaşma düzeyi, fiyat kazanç oranı, hisselerinin $\mathrm{ABD}$ borsalarında işlem görüp görmediği, toplam piyasa değeri, işlem hacmi ve nakit düzeyi gibi firmaya özgü faktörler, literatürde yer bulan çalışmaların (Tablo 2) analizlerinde bağımsız değişken olarak kullanılmıştır. Anlaşılacağı üzere, yabanc1 yatırımcıların hisse senedi tercihlerine etki ettiği düşünülen firmaya özgü çokça faktör, çalışmalarda analizlere dâhil edilmiştir. 
Tablo 2: Konu ile ilişkili Olarak Literatürde Yer Bulan Çalışmalar.

\begin{tabular}{|c|c|c|c|}
\hline $\begin{array}{l}\text { Çalışmanın } \\
\text { Yazar(lar)ı }\end{array}$ & $\begin{array}{c}\text { Çalışmanın } \\
\text { Veri Seti }\end{array}$ & Yöntem & Sonuç \\
\hline $\begin{array}{l}\text { Kang ve } \\
\text { diğerleri, } \\
\text { (1997). }\end{array}$ & $\begin{array}{l}\text { 1975-1991 yılları arasında } \\
\text { Japon borsasında işlem gören } \\
\text { firmalara ait veri seti }(1975 \\
\text { y11 için 503, } 1991 \text { y1lı için de } \\
1.439 \text { firma). }\end{array}$ & 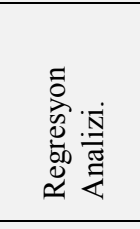 & $\begin{array}{l}\text { Yabancı yatırımcılarca tercih edilen hisselere ait özelliklerin } \\
\text { analiz edildiği çalışmada; Amerikan saklama sertifikası (ADR) } \\
\text { ihraç etmiş, ciro payı fazla, üretim sektöründe yer alan, genel } \\
\text { olarak büyük ancak küçük firmalardan da ihracat payı yüksek, } \\
\text { sistematik olmayan riski ve kaldıraç oranı düşük olan firmaların } \\
\text { daha fazla yabancı yatırımcı çektiği tespit edilmiştir. }\end{array}$ \\
\hline $\begin{array}{l}\text { Dahlquist ve } \\
\text { diğerleri, } \\
\text { (2004). }\end{array}$ & $\begin{array}{l}\text { Yabancı yatırımcılar } \\
\text { tarafından 1993-1998 yılları } \\
\text { arasında İsveç borsasında } \\
\text { yapılan portföy yatırımlarına } \\
\text { ilişkin veri seti. }\end{array}$ & 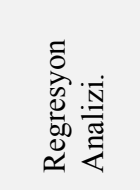 & $\begin{array}{l}\text { Yabancı yatııımı işlemleri ile borsa getirisi arasındaki ilişkinin } \\
\text { incelendiği çalışmanın sonuçlarından biri de yabancı } \\
\text { yatırımcıların; sermaye maliyetlerinde büyük düşüşler } \\
\text { gerçekleştiren, büyük ve iyi tanınan firmaları tercih ettiğidir. }\end{array}$ \\
\hline $\begin{array}{l}\text { Edison ve } \\
\text { diğerleri, } \\
\text { (2004). }\end{array}$ & $\begin{array}{l}\text { 1994-1997 yılları arasında } 9 \\
\text { gelişmekte olan ülke } \\
\text { borsasında yer alan firmalara } \\
\text { ait veri seti. }\end{array}$ & 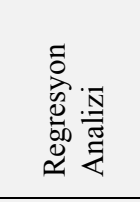 & $\begin{array}{l}\text { Gelişmekte olan piyasalarda yabancı yatırımcı niteliğinde olan } \\
\text { Amerikalı yatırımcılar (bölgesel farklılıklar göstermesine } \\
\text { rağmen); hisse senedi getiri oranı, aktiff karlılık oranı ve betası } \\
\text { yüksek, kaldıraç oranı düşük ve hissesi ABD borsalarında da } \\
\text { işlem gören firmaları tercih etmektedir. }\end{array}$ \\
\hline $\begin{array}{l}\text { Liljeblom ve } \\
\text { diğerleri, } \\
(2005)\end{array}$ & $\begin{array}{l}\text { 1993-1998 yılları arasında } \\
\text { Helsinki borsasında işlem } \\
\text { gören } 51 \text { firmaya ait veri seti. }\end{array}$ & 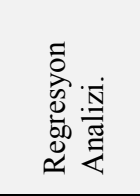 & $\begin{array}{l}\text { Yabancı portföy yatırımlarının belirleyici unsurlarının } \\
\text { incelendiği çalışmada, yabancı yatırımııların; büyük ölçekli, } \\
\text { düşük temettü verimi sağlayan, hissesinin likidite derecesi ve } \\
\text { yatırılan sermayenin getirisi oranı (ROI) yüksek firmaları tercih } \\
\text { ettiği ortaya konulmuştur. }\end{array}$ \\
\hline $\begin{array}{l}\text { Cai ve diğerleri, } \\
\text { (2006). }\end{array}$ & $\begin{array}{l}\text { 1994-2000 yılları arasında } \\
\text { ABD borsalarında işlem gören } \\
4.543 \text { firma verisi. }\end{array}$ & 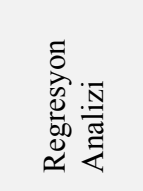 & $\begin{array}{l}\text { ABD borsalarındaki yerli ve yabancı yatırımcıların hisse } \\
\text { tercihlerinin incelendiği çalışmada, yabancı yatırımcıların; } \\
\text { büyük ölçekli, hissesinin likidite derecesi yüksek ve } \\
\text { uluslararasılaşmaya yönelen firmaları tercih ettiği ortaya } \\
\text { konulmuştur. }\end{array}$ \\
\hline $\begin{array}{l}\text { Ko ve diğerleri, } \\
(2007) \text {. }\end{array}$ & $\begin{array}{l}\text { 1986-2001 yılları arasında } \\
\text { Tokyo borsasında işlem gören } \\
\text { yaklaş1k } 1.045 \text { ve } 1993-2002 \\
\text { yılları arasında da Kore } \\
\text { borsasında işlem gören } \\
\text { yaklaşı } 323 \text { firma verisi. } \\
\end{array}$ & 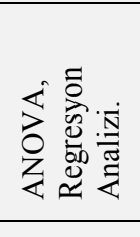 & $\begin{array}{l}\text { Yabancı ve kurumsal yatırımcılarca tercih edilen hisse } \\
\text { senetlerine ait özelliklerin analiz edildiği çalışmanın sonucunda, } \\
\text { yabancı yatırımcıların; toplam piyasa değeri yüksek, defter } \\
\text { değeri-piyasa değeri oranı düşük ve hisse senedi getiri oranının } \\
\text { yüksek olduğu firmaları tercih ettiği ortaya konulmuştur. }\end{array}$ \\
\hline $\begin{array}{l}\text { Kandır } \\
(2008) \text {. }\end{array}$ & $\begin{array}{l}\text { Türkiye'nin en büyük } 1000 \\
\text { firmasının 2000-2004 yılları } \\
\text { arasındaki verileri. }\end{array}$ & 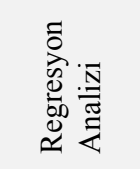 & $\begin{array}{l}\text { Yabancı yatırımcıların hisse tercihlerimi analiz etmeyi amaç } \\
\text { edinen çalışmanın sonucunda; firma satış hacminin, karlılık } \\
\text { göstergelerinin ve ihracat gelirlerinin yabancı yatırımcıların } \\
\text { kararlarında etki sahibi olduğu ortaya konulmuştur. }\end{array}$ \\
\hline $\begin{array}{l}\text { Bae ve diğerleri, } \\
(2011) \text {. }\end{array}$ & $\begin{array}{l}1996-2002 \text { yılları arasında } \\
\text { Kore borsasında işlem gören } \\
70 \text { firma verisi. }\end{array}$ & 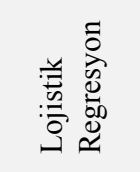 & $\begin{array}{l}\text { Yerli ve yabancı yatırımcıların yatırım davranışı ve } \\
\text { performansının analiz edildiği çalışmanın sonuçlarından biri de; } \\
\text { yabancı yatırımcıların, yüksek temettü kazancı sağlayan, piyasa } \\
\text { değeri yüksek hisselere yatırım yaptığıdır. }\end{array}$ \\
\hline $\begin{array}{l}\text { Lu ve diğerleri, } \\
(2012) \text {. }\end{array}$ & $\begin{array}{l}\text { 2000-2008 yılları arasında } \\
\text { Tayvan borsasında işlem } \\
\text { gören } 247 \text { firma verisi. }\end{array}$ & 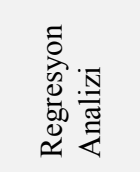 & $\begin{array}{l}\text { Yabancı yatırımcılarca sahip olunan hisse senedi değgşimlerinin } \\
\text { anormal getiriler üzerindeki etkisinin (sürü etkisinin) incelendiği } \\
\text { çalışmanın sonuçlarından biri de; yabancı yatırımcıların büyük } \\
\text { firma hisselerini seçme eğiliminde olduklarıdır. }\end{array}$ \\
\hline $\begin{array}{l}\text { Abdioglu ve } \\
\text { diğerleri, (2013) }\end{array}$ & $\begin{array}{l}\text { 1999-2008 yılları arasında } \\
\text { ABD borsalarında işlem gören } \\
\text { firma verileri. }\end{array}$ & 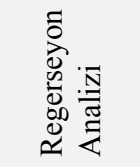 & $\begin{array}{l}\text { Kurumsal yabancı yatırımcıların hisse tercihlerine etki eden } \\
\text { faktörlerin analiz edildiği çalışmanın sonucunda; yabancı } \\
\text { yatırımcıların, kurumsal yönetim anlay'1şı kuvvetli olan firma } \\
\text { hisselerini tercih ettikleri ortaya konulmuştur. }\end{array}$ \\
\hline
\end{tabular}


Yerli ve yabancı tüm yatırımcıların hisse tercihlerine etki eden en önemli faktörlerden biri de firma finansal tabloları ve bu tabloların sunduğu bilgilerdir. Şöyle ki Damodaran'a (2001) göre, yatırımcılar, genel olarak bir firmayı (hisse senedini) değerlerken üç temel bilgi kaynağına başvururlar; bunlar, firmanın bulunduğu sektördeki rakipleri, firma geçmişine ait bilgiler ve firma finansal tablolarıdır. Finansal tablolar, bir firmayı değerlerken kullanılacak en önemli enstrümandır. Finansal tablolar, firma varlıklarının ne derece etkili kullanıldığına, firmanın gelecekteki nakit akımlarının ne olacağına ve işletme faaliyetlerinin sonuçları gibi birçok unsura ait bilgilerin elde edilmesine imkân tanımaktadır (Akdoğan ve diğerleri, 2007). Sözü edilen imkânın tanınması, finansal rasyoların analiz edilmesine bağlıdır. Finansal rasyolar, firma finansal tablolarında bulunan hesap kalemlerinin birbirlerine oranlanmas1 suretiyle tespit edilmekte ve firmanın geçmişine ve geleceğine yönelik önemli yargılarda bulunulmasını mümkün kılmaktadır. Anlaşılacağı üzere finansal tablolarca sunulan bilgiler, yatırımcılar için hisse (firma) seçiminde önemli bir kaynaktır.

$\mathrm{Bu}$ önemine rağmen, literatürde, salt finansal tablo verilerinin yabancı yatırımcıların hisse tercihini ne yönde ve nasıl etkilediğini ortaya koyan ayrıntılı bir çalışmaya henüz rastlanılamamıştır. İlgili tespit, bu çalışmanın yapılmasında en önemli isteklendirici unsur olmuştur.

Yinelemek gerekirse bu çalışmanın temel amacı, BİST'de işlem gören firmalara ait finansal tablo verilerinin, yabancı portföy yatırımcılarının hisse senedi tercihleri üzerindeki etkisini incelemektir. İlgili amaca sahip çalışmanın literatürde yer bulan çalışmalardan amaç yönünden ayrışarak literatüre katkı sağlayacağı umulmaktadır.

\section{VERİ ve METODOLOJI}

Belirlenen amaç doğrultusunda çalışmada; hisseleri BİST'de işlem gören 193 firmanın 2004/12-2014/09 dönemi aralığındaki 3'er aylık finansal tablo verileri ile her bir firma için yabancı yatırımcıların aylık net hisse alım-satım miktarları (adet cinsinden) veri olarak kullanılmıştır. Veriler, FINNNET 2000 veri tabanından temin edilmiştir. Mart 2015 dönemi itibariyle borsadaki şirket sayısı 431'e ulaşmış olsa da 129 mali sektör firmasının ve ilgili dönem boyunca kesintisiz verisine ulaşılamayan 109 firmanın çalışma kapsamı dişında tutulması nedeniyle çalışmada, 193 firma finansal tablo verisi kullanılabilmiştir. Veri kaybının yaşanmaması ve yazında 3'er aylık finansal tablo kullanan çalışmalara (Tsai ve diğerleri, 2011; Bozkurt, 2014) da rastlanıldı̆̆ için ihtiyaç duyulan rasyolar, 3'er aylık finansal tablolardan temin edilmiştir. Çalışmada, 3 likidite rasyosu, 6 faaliyet rasyosu, 6 finansal yapı rasyosu, 5 karlılık rasyosu ve 3 piyasa performans rasyosu olmak üzere toplam 23 finansal rasyo kullanılmıştır. Her bir firma için 40 dönem ve her bir dönemde 23 rasyo analiz edildiğinden dolayı 193 firmanın temel alındığı çalışmada toplam 177.560 adet rasyo verisi hesaplanmıştır. Çalışmanın bağımsız değişkenlerini teşkil eden ilgiili rasyolara ilişkin detaylar Tablo 3'de, temel istatistiki bilgiler ise EK-1'de sunulmuştur. 
Tablo 3: Çalışmanın Bağımsız Değişkenlerini Teşkil Eden Rasyolar.

\begin{tabular}{|c|c|}
\hline $\begin{array}{l}\text { LIKIIDITE RASYOLARI } \\
\text { İşletmenin vadesi gelen borçlarını ödeyebilme } \\
\text { gücünü ölçen bu oranlar, dönen varlıklar ile kısa } \\
\text { vadeli borçlar arasındaki ilişkiyi analiz eder. Diğer bir } \\
\text { değişle işletme sermayesinin yeterlilik düzeyini } \\
\text { ortaya koyar. }\end{array}$ & $\begin{array}{l}\text { PIYYASA PERFORMANS RASY OLARI } \\
\text { Özellikle hisse senedi yatırımcıları tarafından ilgilenilen } \\
\text { bu oranlar, işletme performansını ölçmek amacıyla } \\
\text { kullanılmaktadır. }\end{array}$ \\
\hline $\begin{array}{l}\text { Cari Rasyo }(\mathbf{C R})= \\
\text { Dönen Varlıklar / KVYK }\end{array}$ & $\begin{array}{l}\text { Hisse Başına Kar }(\mathbf{H B K})= \\
\text { Net Kar / Hisse Sayısı }\end{array}$ \\
\hline $\begin{array}{l}\text { Asit Test Rasyosu }(\mathbf{A T R})= \\
\text { (Dönen Varlıklar - Stoklar) / KVYK }\end{array}$ & $\begin{array}{l}\text { Fiyat Kazanç Oranı }(\mathrm{FK})= \\
\text { Hisse Senedi Piyasa Değeri / HBK }\end{array}$ \\
\hline $\begin{array}{l}\text { Nakit Rasyosu }(\mathbf{N R})= \\
(\text { Hazır Değerler + Menkul K.) / KVYK }\end{array}$ & $\begin{array}{l}\mathrm{PD} / \mathrm{DD}(\mathbf{P D})= \\
\text { Piyasa Değeri / Defter Değeri }\end{array}$ \\
\hline
\end{tabular}

\section{FAALIYET RASYOLARI}

$\mathrm{Bu}$ oranlar işletme varlıklarının ne derece etkili kullanıldı̆̆ını göstermektedir. Likidite oranları, likidite tanımında geçen kısa vadeli borçların ödenebilme gücünü ölçerken; faaliyet oranları ise yine likidite tanımında geçen varlıkların ne derece hızla nakde dönüştüğünü ölçer.

Stok Devir Hızı (Y1llı*) $($ SDH) $=$

Satışların Maliyeti / Ortalama Stok

Alacak Devir Hızı (Yıllık*) (ADH) =

Kredili Satış / Ortalama Ticari Alacak

Dönen Varlık Devir Hızı (Yıllık*) (DDH) =

Net Satışlar / Ortalama Dönen Varlıklar

\section{FINANSAL YAPI RASYOLARI}

$\mathrm{Bu}$ oranlar, ağırlıklı olarak uzun vadeli borçların ödenebilme gücünü, varlık kaynak uyumuna ne derece riayet edildiğini ve işletme borçlarının getirdiği sonuçları analiz etmek için kullanılır.

Borç / Aktifler \% (BA)

Borç / Özsermaye \% (BÖ)

Kısa Vadeli Borç / Aktifler \% (KVA)

\section{KARLILIK RASYOLARI}

$\mathrm{Bu}$ oranlar, işletme faaliyetlerinin karlı bir şekilde yürütülüp yürütülmediğini ölçer.

Aktif Karlılık (Y1llık) \% (AK) =

Dönem Net Karı / Aktif Toplamı

Brüt Kar Marjı \% (BKM) =

Brüt Satış Karı / Net Satışlar

Esas Faaliyet Karı Marjı (Yıllık) \% (FKM) =

Faaliyet Karı / Net Satışlar
Maddi Duran Varlık Devir Hızı (Y 1llı*) $(\mathbf{M D H})=$ Net Satışlar / Ortalama Maddi Duran Varlıklar

Aktif Devir Hızı (Yıllık*) (AKDH) = Net Satışlar / Ortalama Aktif Toplamı

Ticari Borç Devir Hızı (Yıllık*) (BDH) = Satışların Maliyeti / Ortalama Ticari Borç

*, İlgili rasyoların paydasında yer alan ortalama hesabl, ilgili yılın ilgili dönemine ilişkin bir hesap kalemi ile aynı hesap kaleminin bir önceki yılın aynı dönemine ilişkin tutarlarına ait ortalarnayı ifade etmektedir. Sözgelimi 2010/09 dönemindeki ortalama ticari alacak tutarı, 2009/09 ile 2010/09 dönemlerine ait alacak kalemlerinin ortalamasinı ifade etmektedir.

NOT: Illgili finansal rasyolar, çalışmanın ilerleyen bölümlerinde, parantez içerisinde koyu yazılan kısaltmalar ile temsil edilecektir.

Firma finansal rasyoları ile yabancı yatırımcıların firma (hisse) tercihleri arasındaki ilişki, panel veri regresyon analizi ile incelenmiştir. Panel veri regresyon analizinin, değişkenler arasındaki sahte ilişkiler nedeniyle yanıltıcı sonuçlar vermemesi, analize dâhil edilen değişkenlerin durağan olmasına bağlıdır. Bu nedenle panel veri regresyon analizi öncesinde, değişkenlerin (i) Levin vd. (2002) testi ile ortak birim kök süreçleri, (ii) Im vd. (2003) testi ile 
her birim (firma) için bireysel birim kök süreci ve (iii) Genelleştirilmiş Dickey vd. (ADF) (1979) testi ile birimlerden bağımsız serilerde birim kök süreci incelenmiştir. Test sonuçlarına (Tablo 4) göre MDH ve OMDV dişındaki tüm değişkenlerin düzeyde durağan olduğu tespit edilmiştir. MDH ve OMDV değişkenleri ise 1. farkı alınarak durağan hale getirilmiştir.

Tablo 4: Panel Birim Kök Testi Sonuçları

\begin{tabular}{|c|c|c|c|c|c|c|c|}
\hline \multirow[b]{2}{*}{ Değişkenler } & \multicolumn{3}{|c|}{ Durağanlığı Test Eden Yöntemler } & \multirow[b]{2}{*}{ Değgişkenler } & \multicolumn{3}{|c|}{ Durağanlığ1 Test Eden Yöntemler } \\
\hline & Levin vd. & Im vd. & ADF & & Levin vd. & Im vd. & ADF \\
\hline$C R$ & $-5.06187 *$ & $-9.50139 *$ & $777.420^{*}$ & $B A$ & $-3.68615 *$ & $-4.96930 *$ & $565.368^{*}$ \\
\hline ATR & $-5.50044 *$ & $-10.7209 *$ & $813.288^{*}$ & $B \ddot{O}$ & $-4.78815^{*}$ & $-10.3628 *$ & $932.979 *$ \\
\hline$N R$ & $-5.29699 *$ & $-20.2836^{*}$ & $1143.57 *$ & $K V A$ & $-6.65786^{*}$ & $-10.0806^{*}$ & $747.373^{*}$ \\
\hline$S D H$ & $-9.11964 *$ & $-10.8234^{*}$ & $802.730 *$ & $F K V$ & $-3.43896^{*}$ & $-4.88091 *$ & $313.530 *$ \\
\hline$A D H$ & $-12.0465^{*}$ & $-11.4537^{*}$ & $780.914^{*}$ & $\ddot{O} A$ & $-3.32484^{*}$ & $-4.59068 *$ & $577.249 *$ \\
\hline$D D H$ & $-12.2414 *$ & $-14.7949 *$ & $939.475 *$ & $\ddot{O} M D V^{\Delta}$ & $-41.6927^{*}$ & $-48.4091 *$ & $2899.59 *$ \\
\hline$M D H^{\Delta}$ & $-19.8003^{*}$ & $-39.6272 *$ & $2327.06^{*}$ & $A K$ & $-5.51882 *$ & $-14.4211 *$ & $877.245^{*}$ \\
\hline$A K D H$ & $-8.98344 *$ & $-11.7820^{*}$ & $801.685^{*}$ & $B K M$ & $-13.0626^{*}$ & $-16.2880 *$ & $1051.34 *$ \\
\hline$B D H$ & $-21.0690 *$ & $-22.3503 *$ & $1327.79 *$ & $F K M$ & $-8.44861 *$ & $-14.9040 *$ & $937.845^{*}$ \\
\hline$H B K$ & $-9.18596^{*}$ & $-16.5668 *$ & $931.481 *$ & $N K M$ & $-7.83767^{*}$ & $-16.7548 *$ & $998.071 *$ \\
\hline$F K$ & $-24.9391 *$ & $-32.5376^{*}$ & $1890.10 *$ & $O K$ & $-9.19319^{*}$ & $-17.9504 *$ & $1037.03 *$ \\
\hline$P D$ & $-5.36773 *$ & $-12.8768 *$ & $838.071 *$ & $I$ & $-57.1107 *$ & $-44.9039 *$ & $2525.26^{*}$ \\
\hline
\end{tabular}

Panel veri regresyon analizi, zaman serisi verileri ile yatay kesit verilerini birleştirerek, kesit analizinden farklı olarak birimlerin zaman boyutunda gözlenmesine ve zaman serisi analizinden farklı olarak da birden fazla birimin gözlemlenmesine (Frees, 2004: 2) ve istatistiki ilişkilerin tespiti için oluşturulan modellerin bünyesinde yer alanı değișkenlerle ilgili olabilen ve gözlenemeyen özel etkilerin kontrol edilmesine (Hausman ve diğerleri, 1981: 1377) imkan tanımaktadır. N sayıda birimin T dönemlik zaman serisi verilleri dikkate alınarak ortaya konulan panel veri denklemi en genel şekliyle şu şekilde ifade edilebilir (Denklem 1):

$$
\mathrm{Y}_{\mathrm{it}}=\beta_{1 \mathrm{it}}+\beta_{2 \mathrm{it}} X_{2 \mathrm{it}}+\ldots+\beta_{\mathrm{Kit}} X_{\mathrm{Kit}}+\varepsilon_{\mathrm{it}}
$$

$\beta=$ Regresyon katsayıları.

$\mathrm{Y}_{\mathrm{it}}=$ Bağımlı değişkenin i. birim için t zamanındaki değeri.

$\mathrm{X}_{\mathrm{Kit}}=\mathrm{K}$ bağımsız değişkeninin i. birim için $\mathrm{t}$ zamanındaki değeri.

Panel veri regresyon denkleminde (Denklem 1) yer alan sabit terim $\left(\beta_{1 \mathrm{it}}\right)$ ile ilgili olarak yapılan farklı varsayımlara göre, farklı regresyon modellerin oluşturulması mümkündür (Judge ve diğerleri, 1985). Buna göre panel veri analizi; sabit terimin, her yatay kesit birim için farklı sabit bir değer aldığı durumlarda "Sabit Etkiler Modeline - SEM" (Denklem 2), aksine sabit terimin yatay kesit birimlere tamamen tesadüfi dağıldığ "Tesadüfi Etkiler Modeline - TEM" (Denklem 3) uygun bir şekilde gerçekleştirilir (Greene, 2003). TEM'deki sabit terim $\left(\bar{\beta}_{1}\right)$, bütün kesit birimlerinin ortalama sabiti olup her kesit birimin sabit teriminde meydana gelen değişiklikler, modele hata teriminin bir bileşeni " $\mu_{\mathrm{i}}$ " olarak dâhil edilir.

$$
\begin{gathered}
\mathrm{Y}_{\mathrm{it}}=\beta_{1 \mathrm{i}}+\beta_{2} \mathrm{X}_{2 \mathrm{it}}+\ldots+\beta_{\mathrm{K}} \mathrm{X}_{\mathrm{Kit}}+\varepsilon_{\mathrm{it}} \\
\mathrm{Y}_{\mathrm{it}}=\bar{\beta}_{1}+\beta_{2} \mathrm{X}_{2 \mathrm{it}}+\ldots+\beta_{\mathrm{K}} \mathrm{X}_{\mathrm{Kit}}+\varepsilon_{\mathrm{it}}+\mu_{\mathrm{i}}
\end{gathered}
$$


Panel veri regresyon analizinin hangi modele göre yapılacağı ise her iki modele göre yapılan regresyon katsayı tahminleri arasındaki farkın istatistiksel olarak anlamlılığının test edilmesini gerektirmektedir. Bu amaç doğrultusunda da çalışmada, tesadüfi etkiler modelinin geçerliği olduğu hipotezini test eden (Greene, 2003) Hausman Testi yapılmıştır. Hausman Testinin sonuçları, Tablo 5 'de sunulmaktadır.

Tablo 5: Hausman Testi Sonuçları

\begin{tabular}{cccl}
\hline Test Özeti & İstatistik & Serbestlik Derecesi & Olasllk \\
\hline Tesadüfi yatay kesit & 7.059700 & 23 & 0.9994 \\
\hline
\end{tabular}

Hausman test sonucuna ait olasılık değerinin $\% 5$ 'den büyük çıkması, panel veri regresyon analizinin tesadüfi etkiler modeli ile yapılacağını ortaya koymaktadır. Çalışma kapsamında oluşturulan model, Denklem 4'te gösterilmektedir.

$$
\mathrm{I}_{\mathrm{i}, \mathrm{t}+1}=\bar{\beta}_{1}+\beta_{2} \mathrm{X}_{1, \mathrm{it}}+\ldots \ldots+\beta_{24} \mathrm{X}_{23, \mathrm{it}}+\varepsilon_{\mathrm{it}}+\mu_{\mathrm{i}}
$$

Modelde yer alan $\beta_{1}, \beta_{2} \ldots \beta_{24}$, bağımsız değişken katsayılarını; i, firmayı; t, zamanı göstermektedir. Ayrıca $X_{1} \ldots X_{23}$, Tablo 3'te yer alan finansal rasyoları ve " $I_{i}$ " de firma finansal tablolarının kamuoyuna sunulduğu ayı takip eden ayda, i firma hisselerinin yabancılarca alınan-satılan net miktarlarını ifade etmektedir. Son olarak $\varepsilon_{i t}$ ise hata terimidir.

\section{BULGULAR ve YORUM}

Denklem 4 ile oluşturulan model sonuçlarına ilişkin sağlıklı yorumlar yapılabilmesi, panel veri regresyon analizinin dayanağını oluşturan varsayımların doğrulanmasına bağlıdır. $\mathrm{Bu}$ varsayımlardan bazısı (Gujarati, 2006); (i) çoklu doğrusal bağlantının, (ii) otokorelasyonun ve (iii) değişen varyansın olmadığı varsayımlarıdır. Panel verilerin kullanıldığı regresyon analizlerinde, doğal olarak çoklu doğrusal bağlantı sorununun azaldığı (Tatoğlu, 2013: 12) bilinmektedir; kaldı ki çalışmada, EK 1'de sunulan korelasyon matrisindeki değişkenlerden yüksek derecede korelasyona sebep olan PD, BA, KVA, FKM, ATR ve NR değişkenleri de analiz dışında tutularak çoklu doğrusal bağlantı sorunu ortadan kaldırılmıştır. Standart hataların düzeltilerek otokorelasyon sorununun önüne geçilmesi amacıyla çalışmada, White'ın yatay kesit kovaryans katsayısı yöntemi kullanılmıştır. Değișen Varyans sorununun önüne geçilmesi amacıyla da çalışmada, GLS (Generalized Least Squares) yöntemi kullanılmıştır. Modele ilişkin otokorelasyon ve değişen varyans varsayımları, sırasıyla Durbin Watson ve Wald istatistikleri ile sınanmıştır.

Finansal rasyoların yabancı yatırımcıların hisse tercihleri üzerindeki etkisini test eden modelin sonuçları Tablo 6'da sunulmuştur.

Tablo 6'da yer alan F istatistiği ve istatistiğin "p" değeri, panel veri regresyon analizi ile oluşturulan modelin \%5'lik anlamlılık düzeyinde bir bütün olarak anlamlı olduğunu, Durbin Watson istatistik değeri ise modelde otokorelasyon olmadığını ortaya koymaktadır. "Değiştirilmiş Wald Testi"nin Ki-kare (Chi-square) istatistiği 1,9234 ve olasılık değeri de 0,58 olarak tespit edilmiştir; istatistiğe ait olasılık değerinin \% $\%$ 'ten büyük olması, değişen varyans sorununun olmadığını açığa çıkarmıştır. Dile getirilen bu sonuçlar, modele ilişkin güvenilir yorumların ve tahminlerin yapılabilmesine imkân tanımıştır. 
Model sonuçlarına göre (Tablo 6), SDH ve NKM değişkenleri ile yabancı portföy yatırımcılarının net hisse alım-satım miktarları arasındaki ilişki \%1 anlamlılık seviyesinde istatistiksel olarak anlamlı bulunmuştur. CR değişkeni ile yabancı yatırımcıların hisse tercihleri arasındaki ilişki \%5 anlamlılık seviyesinde anlamlı iken BO ile FKV değişkenleri ile yabancı yatırımcıların hisse tercihleri arasındaki ilişki ise \% 10 anlamlılık seviyesinde anlamlı bulunmuştur.

Tablo 6: Panel Veri Analizi Sonuçları.

\begin{tabular}{|c|c|c|c|c|}
\hline $\begin{array}{l}\text { Bağımlı Değişken: I } \\
\text { Yöntem: Tesadüfi Etkili Panel Veri } \\
\text { Yatay Kesit Veri Sayısı: } 193 \\
\text { Toplam Panel Veri Sayısı: } 7720 \\
\text { White cross-section standard errors }\end{array}$ & $\begin{array}{l}\text { gresyon Analiz } \\
\text { covariance (d.f. }\end{array}$ & rected) & & \\
\hline Bağımsız Değşsikenler & Katsayılar & Std. Hatalar & t-İstatistiklieri & Olasılık \\
\hline$A D H$ & -0.959089 & 5.474070 & -0.175206 & 0.8609 \\
\hline$A K$ & 859.5534 & 986.9926 & 0.870881 & 0.3838 \\
\hline$A K D H$ & 587.0694 & 52994.36 & 0.011078 & 0.9912 \\
\hline$B D H$ & -130.6616 & 177.9981 & -0.734061 & 0.4629 \\
\hline$B K M$ & -0.445380 & 0.381460 & -1.167565 & 0.2430 \\
\hline BO & 9.082561 & 5.730100 & 1.585061 & 0.0930 \\
\hline$C R$ & 104.8786 & 46.71486 & 2.245080 & 0.0248 \\
\hline$D D H$ & -718.6863 & 2508.266 & -0.286527 & 0.7745 \\
\hline$F K$ & -33.77115 & 23.89598 & -1.413257 & 0.1576 \\
\hline$F K V$ & -4225.651 & 2409.523 & -1.753729 & 0.0795 \\
\hline$H B K$ & -10010.83 & 9357.051 & -1.069870 & 0.2847 \\
\hline$M D H$ & -1.730036 & 16.06886 & -0.107664 & 0.9143 \\
\hline SDH & -8.260958 & 2.550529 & -3.238919 & 0.0012 \\
\hline$N K M$ & 0.001174 & $7.23 \mathrm{E}-05$ & 16.23635 & 0.0000 \\
\hline$O A$ & 176.3204 & 1563.425 & 0.112778 & 0.9102 \\
\hline$O K$ & -28.34528 & 52.19789 & -0.543035 & 0.5871 \\
\hline$O M D V$ & -1.778771 & 2.665871 & -0.667238 & 0.5046 \\
\hline C & 9048.745 & 651.1115 & 13.89738 & 0.0000 \\
\hline Belirlilik Katsayıs $\left(\mathrm{R}^{2}\right)$ & 0.010790 & & Düzeltilmiş $\mathrm{R}^{2}$ & 0.002892 \\
\hline F-İstatistiği & 1.396918 & & İstatistiği p Değeri & 0.028150 \\
\hline Değiştirilmiş Wald Testi & 1.923400 & & ald Testi p Değeri & 0.5885 \\
\hline & & Durk & -Watson İstatistiği & 2.393077 \\
\hline
\end{tabular}

Bulgular; yabancı yatırımcıların, SDH'ı (stok devir hızı) ve FKV (Kısa vadeli finansal borç / kısa vadeli borç) oranı artan firma hisselerinde net satıma yönelirken NKM (net kar marjı), CR (cari oranı) ve BO (borç / özsermaye) oranı artan firmalarda ise net alıma yöneldiğini ortaya koymaktadır. Başka bir değişle yabancı yatırımcılar, net kar marjını, cari oranını ve borç/özsermaye oranını artıran buna karşın stok devir hızını ve FKV oranını düşüren firma hisselerini tercih etmektedirler; yani bu hisselerde alışa geçmektedirler.

Yukarıda yer verilen bulgulara ilişkin şu yorumlar yapılabilir.

1) Vadesi gelen kısa vadeli borçlarını, finansmanın uygunluğu ilkesi gereği, dönen varlıkları ile karşılamada zorluk çekmeyen firmalara ait iflas olasılığının azalacak olması; yabancı yatırımcıların, cari oranı yükselen ve kısa vadeli borçları içindeki finansal borçları (FKV) azalan firma hisselerini göreceli olarak daha fazla tercih etmelerinin nedeni olarak yorumlanabilir. 
2) Karlılığını artıran firmaların, gelecekteki nakit akım potansiyelini artıracağ1 ve doğal olarak gelecekteki yüksek nakit akım beklentisinin de hisse fiyatlarını artıracağı düşüncesi, net kar marjı yükselen firma hisselerinin yabancı yatırımcılarca göreceli olarak daha fazla tercih edilmesinin nedeni olarak yorumlanabilir.

3) Borç düzeyi ile hisse değerleri arasındaki ilişkilerin BİST özelinde incelendiği güncel çalışmalarda (Bozkurt, 2014), firmaların borçlanma düzeylerindeki artışların hisse değerlerini artırdığı ortaya konulmuştur. BİST'deki hisse fiyat hareketlerine yön veren esas unsurun yabancı yatırımcılar olduğu kabul edildiğinde, ilgili çalışmalarda ortaya konulan borç ile hisse değeri arasındaki pozitif yönlü ilişkinin temel nedeni olarak bu çalışmanın sonuçları gösterilebilir. Bu çalışmanın sonuçların göre, "borç/özsermaye" oranındaki artışların yabancı yatırımcıların hisse tercihlerine etkisi olumludur; dolayısıyla da hisse senetlerindeki alım yönlü artışlar, hisse senetlerinin fiyatlarını artırmaktadır.

4) Yabancı ortak payının yüksek olduğu firmaların stok seviyesinde azalış ve stok yönetiminde etkinlik yaratıldığı gözlemlenmiştir (Ameer, 2010). Satışlar sabit tutulduğunda stoklarda meydana gelen azalışlar SDH'ını artırır. Buna göre; esas amacı faaliyetlerini daha az stok seviyesi ile etkin bir şekilde sürdürmek olan yabancıların, SDH yüksek olan firmaların hisselerini tercih etmesi beklenir. Ancak bu çalışmanın bulgularına göre yabancılar, SDH düşük olan firmaların hisselerini tercih etmektedirler. Bu sonuç, BİST özelinde, yabancıların, likidetinin stoklar ile sağlanabilmesine önem vermesinden kaynaklanmış olabilir. Şöyle ki işletme sermayesi kalemleri içerisinde stokların oranının artması, likiditenin stoklar ile sağlanabildiğini göstermektedir (Aksoy ve diğerleri, 2008: 77).

\section{SONUÇ}

Yabancı yatırımların; ülke ekonomisini, sermaye piyasalarını ve firmaları önemli derecede olumlu ve olumsuz yönde etkileyebilecek nitelikte olması, yazında, yabancı yatırımcıları temel alan ve bu yatırımcıların yatırım kararlarına etki eden faktörlerin belirlenmesini amaç edinen çokça çalışmanın yapılmasına ortam hazırlamıştır. Yabancı yatırımcıların yatırım (hisse) tercihlerini etkileyen, diğer bir ifadeyle de yabancı sermaye hareketlerine neden olan faktörlerin bilinmesi; (i)uluslararası sermaye hareketlerinin neden olacağı olumsuz ekonomik etkilerin bertaraf edilmesi için alınacak önlemelerin, (ii)hisse senedi piyasalarını kullanarak fon temin etmek isteyen firmaların önem göstereceği hususların, (iii)portföy oluşturma sürecinde yerli yatırımcılarca oluşturulacak stratejilerin ve (iv)yabancı sermaye yatırımlarından sağlanacak olan faydaların nasıl maksimize edileceğinim, tespiti açısından önemlidir. $\mathrm{Bu}$ öneminden dolayı, literatürde yer alan çalışmalarda, yabancı sermaye hareketlerinin nedenlerini açıklamak için birçok faktör incelenmiş; ancak firmalara ait finansal rasyoların, yabancı sermaye hareketleri üzerindeki etkisi ayrıntılı bir şekilde irdelenmemiştir.

$\mathrm{Bu}$ çalışmanın temel amacı; Borsa İstanbul'da işlem gören firmalara ait finansal tablo rasyolarının, yabancı portföy yatırımcılarının hisse senedi tercihleri üzerindeki etkisini incelemektir.

Belirlenen amaç doğrultusunda çalışmada, hisseleri Borsa İstanbul'da işlem gören 193 firmanın 2004/12-2014/09 dönemi aralığındaki 3'er aylık finansal tablo verileri ile her bir firma için yabancı yatırımcıların aylık net hisse alım-satım miktarları (adet cinsinden) veri olarak kullanılmıştır. Çalışmada, 3 likidite rasyosu, 6 faaliyet rasyosu, 6 finansal yapı rasyosu, 5 karlılık rasyosu ve 3 piyasa performans rasyosu olmak üzere toplam 23 finansal rasyo 
kullanılmıştır. Her bir firma için 40 dönem ve her bir dönemde 23 rasyo analiz edildiğinden dolayı 193 firmanın temel alındığı çalışmada toplam 177.560 adet rasyo verisi hesaplanmıştır.

Verilerin panel veri regresyon analiz yöntemi ile analiz edildiği çalışma sonucunda; yabancı yatırımcıların, net kar marjını, cari oranını ve borç/özsermaye oranını artıran buna karşın stok devir hızını ve FKV oranını düşüren firma hisselerinde alım yönlü hareketlere başladıkları ortaya konulmuştur.

Çalışmanın; elde ettiği bulgularıyla ve bulgulara ilişkin yorumlarıyla, hem hisse senedi piyasalarını kullanarak fon temin etmek isteyen firmalara hem de portföy oluşturma sürecinde en uygun stratejiyi belirleme arzusunda olan yerli yatırımcılarca faydalı bilgiler sunduğu, yazında yer bulan çalışmalardan amaç yönünden ayrıştığı ve böylece literatüre katkı sağladığı düşünülmektedir. Sonraki çalışmalarda, finansal rasyoların yabancı yatırımcıların hisse tercihlerine olan etkisi yerine; yabancı yatırımcılarca yoğun bir şekilde tercih edilen firmalarda, yabancı yatırımcı tercihinin hangi finansal rasyolarda ne gibi değişikliklere yol açtığg incelenebilir.

EK 1: Finansal Rasyolara İlişkin Temel İstatistiki Bilgiler ve Korelasyon İlişkisi.

PANEL A: Değişkenlere İlişkin Temel İstatistiki Bilgiler

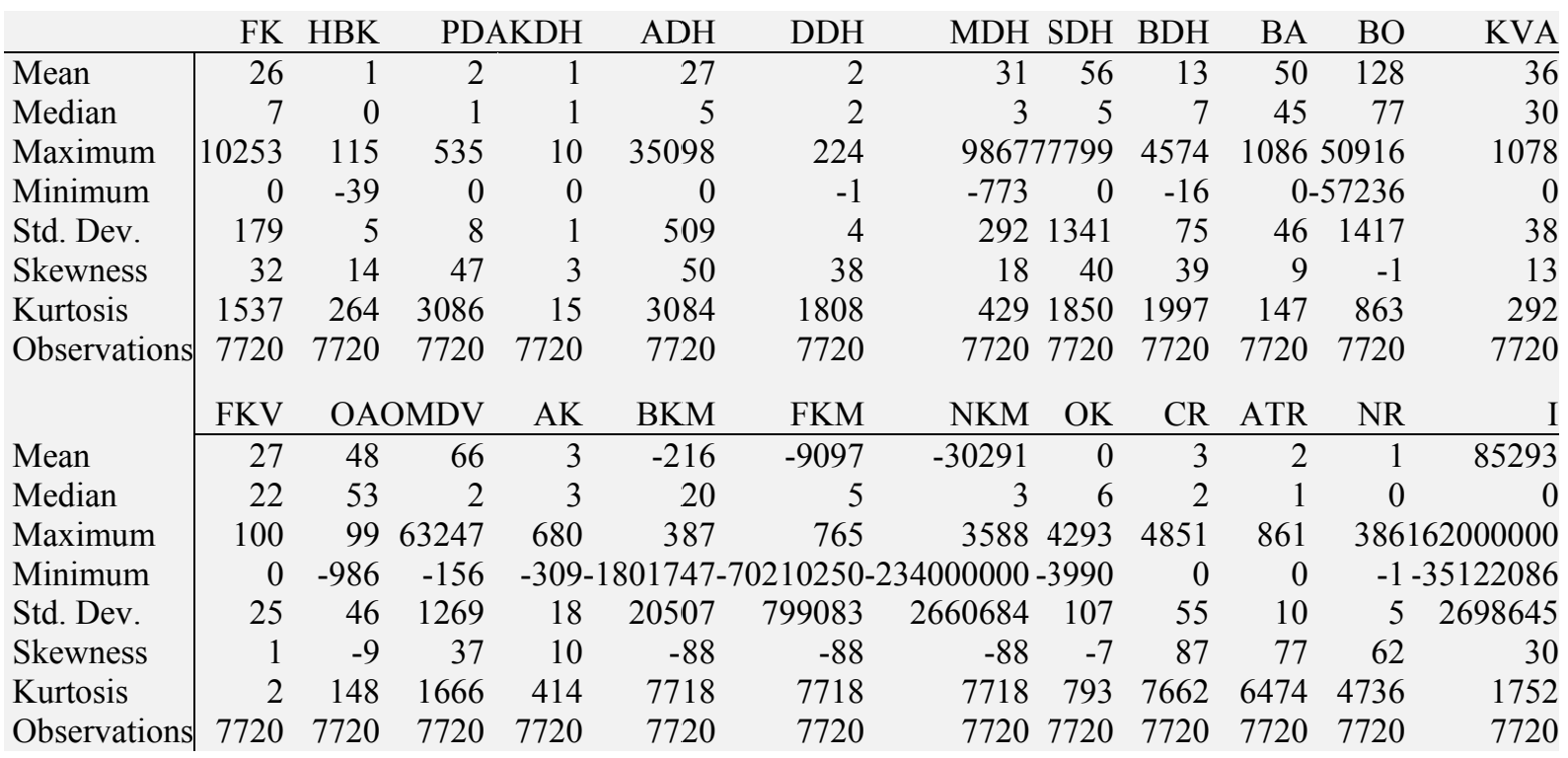


PANEL B: Değişkenler Arasındaki Korelasyon Illişkisi.

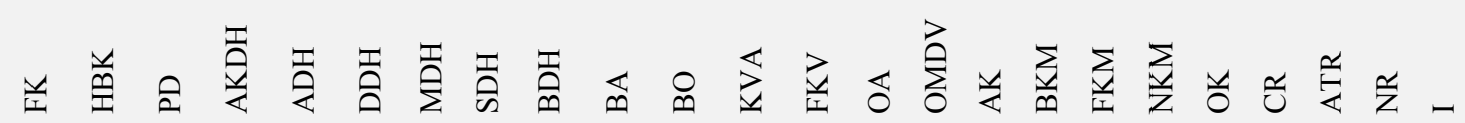

FK 1.00

HBK $0.00 \quad 1.00$

\begin{tabular}{l|lll|l} 
& 0.00 & 0.04 & 1.00 \\
\cline { 2 - 4 } & 0.00 & 0.01 & -0.01 & 1
\end{tabular}

\begin{tabular}{l|lllll}
$\mathrm{AKDH}$ & 0.00 & 0.01 & -0.01 & 1.00 \\
\cline { 2 - 4 }
\end{tabular}

\begin{tabular}{l|llllll|}
$\mathrm{ADH}$ & 0.00 & 0.00 & 0.00 & 0.01 & 1.00 \\
\cline { 2 - 6 }
\end{tabular}

\begin{tabular}{l|l|l|l|l|l|l|}
\cline { 2 - 5 } $\mathrm{DDH}$ & 0.00 & -0.01 & -0.01 & 0.23 & -0.03 & 1.00 \\
\cline { 2 - 5 } & 0.00 & 0.02 & 0.00 & 0.09 & 0.00 & 0.01
\end{tabular}

\begin{tabular}{l|lllllll|l}
$\mathrm{MDH}$ & 0.00 & 0.02 & 0.00 & 0.09 & 0.00 & 0.01 & 1.00
\end{tabular}

\begin{tabular}{l|lllllll|l|l|}
\cline { 2 - 7 } SDH & 0.00 & 0.00 & 0.00 & 0.00 & 0.00 & 0.00 & 0.001 .00
\end{tabular}

\begin{tabular}{l|l|l|l|l|l|l|l|l|l|}
$\mathrm{BDH}$ & 0.00 & 0.01 & 0.00 & 0.02 & 0.00 & 0.02 & 0.04 & 0.00 & 1.00 \\
\cline { 2 - 8 }
\end{tabular}

\begin{tabular}{l|l|l|l|l|l|l|l|l|l|l|l|}
$\mathrm{BA}$ & 0.02 & -0.10 & -0.01 & 0.02 & 0.01 & -0.01 & 0.03 & 0.00 & -0.02 & 1.00
\end{tabular}

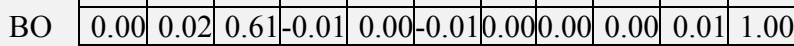

\begin{tabular}{l|l|l|l|l|l|l|l|l|l|l|l|l|}
\hline KVA & 0.03 & -0.06 & 0.01 & 0.01 & 0.00 & -0.02 & 0.02 & 0.00 & -0.02 & 0.82 & 0.01 & 1.00 \\
\cline { 2 - 7 }
\end{tabular}

\begin{tabular}{l|l|l|l|l|l|l|l|l|l|l|l|l|l|} 
FKV & 0.01 & -0.01 & -0.01 & -0.01 & -0.01 & -0.01 & 0.000 .01 & 0.01 & 0.10 & -0.01 & 0.16 & 1.00
\end{tabular}

\begin{tabular}{l|llll|l|l|l|l|l|l|l|l|l|l|}
$\mathrm{OA}$ & -0.02 & 0.10 & 0.01 & 0.05 & -0.01 & 0.04 & 0.01 & 0.00 & 0.02 & -0.93 & -0.01 & -0.80 & -0.08 & 1.00 \\
\hline
\end{tabular}

\begin{tabular}{c|cccccc|c|c|c|c|c|c|c|c|c|}
\hline OMDV & 0.00 & 0.02 & 0.00 & 0.00 & 0.00 & 0.00 & 0.18 & 0.00 & 0.01 & -0.01 & 0.00 & -0.01 & -0.03 & 0.02 & 1.00
\end{tabular}

\begin{tabular}{l|l|l|l|l|l|l|l|l|l|l|l|l|l|l|l|l|l|l|l|} 
AK & -0.03 & 0.19 & -0.01 & 0.03 & 0.00 & 0.000 .01 & 0.00 & 0.01 & -0.57 & -0.01 & -0.49 & -0.06 & 0.59 & 0.01 & 1.00
\end{tabular}

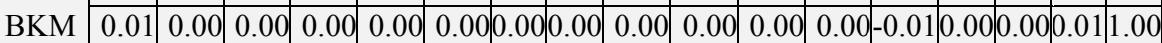

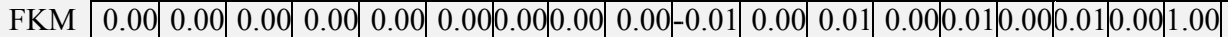

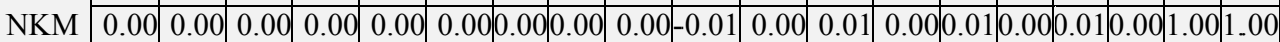

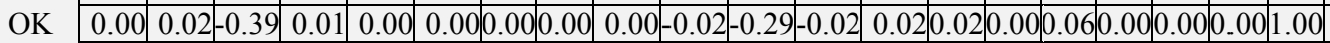

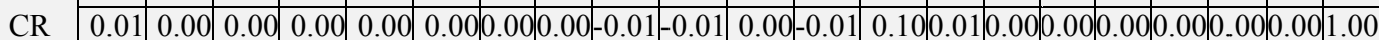

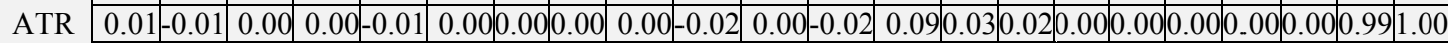

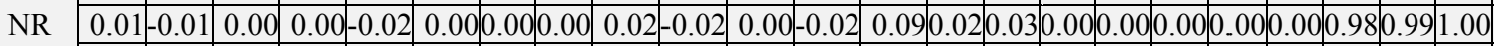

\begin{tabular}{l}
$\mathrm{I}$ \\
\cline { 2 - 6 }
\end{tabular} 


\section{REFERENCES}

- ABDİOGLU, N., KHURSHED, A. ve STATHOPOULOS, K. (2013). Foreign institutional investment: Is governance quality at home important?. Journal of International Money and Finance, 32, 916-940.

- AKDOĞAN N. ve TENKER N. (2007). Finansal Tablolar ve Mali Analiz Teknikleri. Ankara: Gazi Kitabevi.

- AKSOY, A. ve YALÇINER, K. (2008). İşletme Sermayesi Yönetimi. Ankara: Gazi Kitabevi.

- AMEER, R. (2010). The role of institutional investors in the inventory and cash management practices of firms in Asia. Journal of Multinational Financial Management, 20(2), 126-143.

- BAE, S. C., MIN, J. H., ve JUNG, S. (2011). Trading Behavior, Performance, and Stock Preference of Foreigners, Local Institutions, and Individual Investors: Evidence from the Korean Stock Market. Asia-Pacific Journal of Financial Studies, 40(2), 199239.

- BAYRAKTAR, F. (2003). Dünyada ve Türkiye'de doğrudan yabancı sermaye yatırımları. Ankara: Türkiye Kalkınma Bankası.

- BOZKURT, İ. (2014). İflas olasılığı ile sistematik risk ilişkisinin incelenmesi ve etkin iflas göstergesi modellerinin tespiti: bist'de ampirik bir uygulama. Suleyman Demirel University Journal of Faculty of Economics \& Administrative Sciences, 19(4), 127142.

- BOZKURT, İ. (2014). Dengeleme Teorisi'nin Geçerliliğinin Panel Veri Analizi ile Test Edilmesi: BİST'de Ampirik Bir Uygulama. Yönetim ve Ekonomi, 21(2), 163178.

- CAİ, F. ve WARNOCK, F. E. (2006). International diversification at home and abroad (No. w12220). National Bureau of Economic Research.

- DAHLQUIST, M. ve ROBERTSSON, G. (2004). A note on foreigners' trading and price effects across firms. Journal of Banking \& Finance, 28(3), 615-632.

- DAMODARAN A. (2001). Investment Valuation. New York: Wiley.

- DICKEY, D.A. ve FULLER, W.A. (1979). Distribution of The Estimators for Autoregressive Time Series with a Unit Root. Journal of the American Statistical Association, 74 (366), 427-431.

- EDİSON, H. J. ve WARNOCK, F. E. (2004). US Investors' Emerging Market Equity Portfolios: A Security-Level Analysis. Review of Economics and Statistics, 691-704.

- FISCHER, S., COOPER, R. N., DORNBUSCH, R., GARBER, P. M., MASSAD, C., POLAK, J. J. ve TARAPORE, S. S. (1998). Should the IMF pursue capital-account convertibility? (No. 207). International Economics Section, Departement of Economics Princeton University. http://EconPapers.repec.org/RePEc:fth:priifi:207, (21.02.2015).

- FREES E.W. (2004). Longitudinal and Panel Data: Analysis and Applications in the Social Sciences. New York: Cambridge University Press,

- GREENE, W.H. (2003). Econometric Analysis. New Jersey: Prentice Hall, Fifth Edition.

- GUJARATI, D.N. (2006). Temel Ekonometri, (Çev.) Şenesen Ü. ve Şenesen, G.G. İstanbul:Literatür Yayıncılık. 
- HAUSMAN, J.A. ve Taylor, W.E. (1981). Panel Data and Unobservable Individual Effects. Econometrica, 49 (6), 1377-1398.

- IM, K.S., PESARAN, M.H. ve SHIN, Y. (2003). Testing For Unit Roots İn Heterogeneous Panels. Journal of Econometrics, 115 (1), 53-74.

- JUDGE, G.G., GRIFFITHS, W.E., HILL, R.C., LUTKEPOHL, H. ve LEE, T.C. (1985). The Theory and Practice of Econometrics. New York: John Wiley \& Sons, Second Edition.

- KAMESAKA, A., NOFSINGER, J. R. ve KAWAKITA, H. (2003). Investment patterns and performance of investor groups in Japan. Pacific-Basin Finance Journal, 11(1), 1-22.

- KANDIR, S.Y. (2008). Yabancı Yatırımcıların Türkiye'deki Yatırım Tercihlerinin Araştırılması. Muhasebe ve Finansman Dergisi, 38, 199-209.

- KANG, J. K. ve STULZ, R.M. (1997). Why is there a home bias? An analysis of foreign portfolio equity ownership in Japan. Journal of Financial Economics, 46(1), 328.

- KO, K., KIM, K. ve CHO, S. H. (2007). Characteristics and performance of institutional and foreign investors in Japanese and Korean stock markets. Journal of the Japanese and International Economies, 21(2), 195-213.

- LEVIN, A., LIN, C. ve CHU, C.J. (2002). Unit Root Tests İn Panel Data: Asymptotic And Finite-Sample Properties. Journal of Econometrics. 108 (1), 1-24.

- LILJEBLOM, E. ve LÖFLUND, A. (2005). Determinants of international portfolio investment flows to a small market: empirical evidence. Journal of multinational financial management, 15(3), 211-233.

- LU, Y. C., FANG, H. ve NIEH, C. C. (2012). The price impact of foreign institutional herding on large-size stocks in the Taiwan stock market. Review of Quantitative Finance and Accounting, 39(2), 189-208.

- SAĞLAMER, E. (2003). Dolaylı Yabancı Sermaye Yatırımları ve Dış Yatırımcıların Türk Sermaye Piyasasına Çekilmesi. Yayınlanmamış Yüksek Lisans Tezi. Dokuzeylül Üniversitesi, Sosyal Bilimler Enstitüsü, İzmir.

- SAYIN, K.O. (2014). Yabancı İşlemleri Eylül 2014. Gedik Yatırımı Danışmanlığı ve Araştırma Merkezi. www.gedik.com, (19.02.2015).

- TATOĞLU, F. Y. (2013). Panel Veri Ekonometrisi. İstanbul: Beta Yayıncıllk.

- TSAI, C.F., LIN, Y.C., YEN, D.C. ve CHEN, Y.M. (2011). Predicting Stock Returns by Classifier Ensembles. Applied Soft Computing, 11 (2), 2452-2459.

- YALÇINER, K. (2008). Uluslararası Finansman. Ankara: Gazi Kitabevi. 